\title{
Synthesis of Acrylate-Modified Cellulose via Raft Polymerization and Its Application as Efficient Metal Ions Adsorbent
}

\author{
Yasser Assem ${ }^{1 *}$, Ragab E. Abou-Zeid ${ }^{2}$, Korany A. Ali ${ }^{3,4}$, Samir Kamel ${ }^{2}$ \\ ${ }^{1}$ Department of Polymers and Pigments, National Research Centre, 12622 Dokki, Giza, \\ Egypt. \\ ${ }^{2}$ Cellulose and Paper Department, National Research Centre, 12622 Dokki, Giza, Egypt. \\ ${ }^{3}$ Center of Excellence, Advanced Material \& Nanotechnology Group, National Research \\ Centre, 12622 Dokki, Giza, Egypt. \\ ${ }^{4}$ Applied Organic Chemistry Department, National Research Centre, 12622 Dokki, \\ Giza, Egypt.
}

OLY acrylic acid-co-methyl methacrylate was grafted via reversible addition fragmentation
chain transfer polymerization to cellulose. The graft copolymer was characterized by FTIR
spectrum, thermo gravimetric analyzer, and scanning electron microscope. The adsorption
behavior of the grafted cellulose for $\mathrm{Ca}^{2+}, \mathrm{Cu}^{2+}$ and $\mathrm{Pb}^{2+}$ ions was investigated. The adsorption
capacity was improved as the molar ratio of acrylic acid increased. The grafted cellulose showed
good adsorption performance for $\mathrm{Ca}^{2+}$ ion with $97 \%$ rather than $\mathrm{Cu}^{++}$and $\mathrm{Pb}^{++}$. That revealed
the adsorption process increased due to the increase of the $\mathrm{COOH}$ group of acrylic acid, which
improves the chelation activity of the grafted polymer.

Keywords: Cellulose, Graft copolymer, Reversible Addition Fragmentation Chain Transfer (RAFT), Adsorption, Heavy metals.

\section{Introduction}

Water has a wide impact on all aspects of human life like health, food, energy and economics. In the last decades, many methods have been studied for treatment of underground water like; ion exchange, chemical precipitation, nano-filtration, reverse osmosis and adsorption. In particularly, adsorption method has attracted scientific focus due to high availability of different adsorbents, low cost, and easy handling [1]. In recent decade, scientists have focused to prepare adsorbent from new, sustainable, environment-friendly, and inexpensive natural polymer due to variation in raw material prices, international difficulties in raw material supplies, and increasing public consciousness on environmental issues.

Cellulose is the most widespread polymeric raw material in nature and it is obtained from different plants and bacterial sources [2]. In the last few decades, cellulose graft copolymers have gained a substantial interest, due to their unique properties. These properties make them suitable for using in a wide range of applications such as medical, water treatment $[3,4]$, pharmaceutical [5], textiles, filtration, etc. To modify cellulose and control this modification, understanding its structure is a pre-requisite. The molecular structure of cellulose is composed of linear chains of glucose unit with three $\mathrm{OH}$ groups. These groups are capable of forming inter and intra hydrogen bonds, yielding a straight and crystalline chain nature [6,7]. Cellulose has high dense hydrogen bonded network, so it is insoluble in water and most organic solvents. Thus, most cellulose reactions, including polymer grafting, are heterogeneous reactions which carried out at the solid or swollen state. To enhance metalbinding ability of cellulose, the introduction of new functional groups via graft copolymerization is one of the activations of cellulose. Various functional groups can be grafted to cellulose such as acrylonitrile [8], acrylic acid [9] and acrylamide [10].

In the last decades, attempts to minimize the chain transfer and to control the molecular weight polydispersity on the grafted cellulose, a controlled/ "living" radical polymerization methods have been investigated [11]. Among them atom transfer radical polymerization (ATRP) and reversible addition fragmentation transfer polymerization (RAFT) are the two suitable methods to prepare grafted cellulose.

*Corresponding author e-mail: ya.assem@nrc.sci.eg 
In heterogeneous process, polystyrene graft cellulose by a RAFT process was reported by Perrier, et al. [12] and Carlmark et al prepared a poly(2-hydroxyethyl methacrylate) graft cellulose using an ATRP process [13]. Huang, et al. prepared cellulose graft copolymers with different monomers using a homogeneous ATRP process $[14,15]$.

RAFT polymerization is a powerful and useful living polymerization method for synthesizing well-defined, advanced graft polymer features and controlling the polymerization of numerous vinyl monomers over moderate conditions. RAFT can be used to graft various monomers onto solid supports such as silica [16], silicon [17], carbon nanotubes [18], polypropylene, gold, and coreshell microspheres. Also, it has been reported to graft vinyl monomers on cellulosic materials. But there is a very limited study on modification of cellulose via RAFT-mediated graft polymerization. The first modification of cellulose by RAFT polymerization in heterogeneous media was done by Roy \& Perrier [19,20].

In this study, the grafting of polyacrylic acid and polymethylmethacrylate from bagasse cellulose was reported. Preparation and characterization of cellulose-based macro chain transfer agent and its use to mediate the reversible additionfragmentation chain transfer polymerization of acrylic acid and methyl methacrylate are reported. The adsorption of the grafted cellulose for $\mathrm{Ca} 2+$, $\mathrm{Cu} 2+$ and $\mathrm{Pb} 2+$ ions were also investigated.

\section{Experimental}

\section{Materials}

Cellulose was extracted from bagasse pulp which delivered from Quena Paper Industry Company, Egypt. Acrylic acid, dicyclohexylcarbodiimide (DCC), 4-dimethylaminopyridine (DAMP) as a catalyst, 3-mercaptopropionic acid, carbon disulfide, benzyl bromide, chloroform, hydrochloric acid, sodium chloride solution, sodium sulfate, n-hexane and ethyl acetate, potassium hydroxide dichloromethane are from ACROS and used as received.

\section{Preparation of cellulose-RAFT}

Cellulose $(2 \mathrm{~g})$ was immersed into 50 $\mathrm{mL}$ round flask containing RAFT agent $(5 \mathrm{~g})$ dissolved in $15 \mathrm{~mL}$ of dichloromethane (DCM). Dicyclohexylcarbodiimide (DCC) $(0.8 \mathrm{~g}, 4 \mathrm{mmol})$ was dissolved in $10 \mathrm{~mL}$ DCM and added to the cellulose containing reaction flask at room temperature. 4-Dimethylaminopyridine (DMAP) $(0.44 \mathrm{~g}, 3.6 \mathrm{mmol})$ was dissolved in DCM (15 $\mathrm{mL}$ ) and slowly added to the reaction mixture. The reaction mixture was left to stir, at room temperature, on magnetic stirrer for $72 \mathrm{~h}$. At the end of the reaction, the samples were thoroughly washed with different solvents in the following sequence; DCM, THF, THF: water (1:1), water, and methanol. Finally, the product was placed in a drying oven at $50^{\circ} \mathrm{C}$ to dry overnight.

\section{Polymerization}

Cellulose-RAFT $(1 \mathrm{~g})$ was stirred in $10 \mathrm{~mL}$ deionized water for AA homopolymerization and $\mathrm{H} 2 \mathrm{O} / \mathrm{DMF} 70 / 30$ respectively for the AA and MMA copolymerization in $50 \mathrm{~mL}$ Schlenk flask and purged with Argon for $30 \mathrm{~min}$. A degassed stock solution of the monomers acrylic acid and mehylmethacrylate (AA, MMA) and $10 \mathrm{~mL}$ solution of 2,2'-Azobis(2-methylpropionamidine) dihydrochloride (V50) initiator $(0.01 \mathrm{~g} / \mathrm{mL} \mathrm{H} 2 \mathrm{O})$ were prepared. After that the stock solution of the macro-RAFT was placed in an oil bath at 70 ${ }^{\circ} \mathrm{C}$. Then, the required amounts of monomers (at various AA/MMA weight ratios) and initiator were fed into the reactor with dosing rate $1 \mathrm{~mL} /$ min and $0.1 \mathrm{~mL} / \mathrm{min}$ for both monomers and initiator, respectively (Table 1).

The required amount of monomers and initiator were fed with dosing rate $1 \mathrm{~mL} / \mathrm{min}$ and $0.1 \mathrm{~mL} / \mathrm{min}$ for both monomer and initiator respectively, the AA and MMA monomers were fed into the reaction mixture at different AA/ MMA weight ratios (Table 1). After last addition the polymerization reaction was left to run for $8 \mathrm{~h}$ followed by addition of few drops of methanol at the end of polymerization process. The final obtained product was a mixture of grafted cellulose and free homo/copolymers. The grafted cellulose was collected by filtration in a Buchner funnel and subjected to Soxhlet extraction using de-ionized water followed by extraction by THF for $6 \mathrm{~h}$. The grafted cellulose samples were dried in a drying oven at $40{ }^{\circ} \mathrm{C}$ [21].

Cleaving of polymer chains from cellulose backbone

Two transesterification methods (i.e. acidbase catalyzed) were studied to hydrolyze the PAA and PAA-co-PMMA chains from the cellulose backbone. In a base catalyzed hydrolysis experiment, $1 \mathrm{~g}$ of cellulose-g-PAA and celluloseg-PAA-co-PMMA samples was immersed into a 
bottom flask containing $200 \mathrm{~mL}$ of $\mathrm{KOH}(2.0$ $\mathrm{M}$ solution in $\mathrm{H} 2 \mathrm{O})$. The reaction mixture was refluxed for $48 \mathrm{~h}$. After the completion of the reaction, $10 \mathrm{~mL}$ of $\mathrm{H} 2 \mathrm{O} / \mathrm{THF}$ 9/1 was added to the flask and the solid cellulose substrate was removed from the mixture, subsequently the solvents were evaporated. The solid was washed with methanol to remove the excess of $\mathrm{KOH}$; the remaining product (cleaved polymer grafts) was separated by filtration. In case of acid hydrolysis, $0.1 \mathrm{~g}$ cellulose-g-PAA and celluloseg-PAA-co-PMMA samples were immersed into a round-bottomed flask containing $150 \mathrm{~mL}$ of $2.0 \mathrm{M} \mathrm{HCl}$ aqueous solution. The mixture was stirred at $90{ }^{\circ} \mathrm{C}$ for $48 \mathrm{~h}$. The reaction mixture was filtered to separate the solid cellulose particles. Then $200 \mathrm{ml}$ of THF was added and the reaction mixture was stirred for 20 minutes. The organic layer was separated by separating funnel. Upon evaporation of THF, the solid polymer was obtained and was left to dry at 50 ${ }^{\circ} \mathrm{C}$ in a drying oven for $48 \mathrm{~h}$. [22].

\section{Instrumentation and characterization}

Gel permeation chromatography (GPC)

The molecular weights of all polymers were measured by Chloroform GPC at $25^{\circ} \mathrm{C}$. Sample concentration was $1 \mathrm{~g} / \mathrm{L}$. The apparatus consists of a Gynkotek HPLC pump, an Agilent Autosampler 1200, linear columns (PSS, polystyrene) consisting of a pre-column $10 \mu, 8 \times 50 \mathrm{~mm}$, a column $10 \AA, 8 \times 300 \mathrm{~mm}$ and two columns $3000 \AA, 8$ x $300 \mathrm{~mm}$. As detector, RI detector of Knauer Company was used. For calibration, linear PMMA with a narrow mass distribution and molecular weight between 500 and 1,000,000 was used. Toluene was used as an internal standard. The elugram was evaluated with PSS- WinGPC Unity program.

\section{Nuclear magnetic resonance spectroscopy (NMR) \\ ${ }^{1} \mathrm{H}(400.13 \mathrm{MHz}) \mathrm{NMR}$ spectra were recorded on a Bruker DRX-300 spectrometer located at Faculty of Pharmacy Ain Shams University, Egypt. Tetramethylsilane (TMS) was used as an internal standard.}

\section{Infrared spectroscopy (FTIR)}

The IR spectra were measured on a FT-IR spectrometer of type Brucker with an attached IR microscope of the type UMA 600 from Digilab. Infrared spectroscopy (IR) was performed by means of Digilab (Excalibur series) instrument with ATR crystal ZnSe at the Textile Research Division NRC, Egypt.

\section{Thermo gravimetric analysis (TGA)}

The thermal stability of cellulose samples before and after grafting was tested by thermo gravimetric analysis (TGA, Shimadzu DTG-60, Japan) at a heating rate of $10{ }^{\circ} \mathrm{C} / \mathrm{min}$ from 25 to $800{ }^{\circ} \mathrm{C}$ under a nitrogen atmosphere.

\section{Scanning electron microscopy}

Scanning electron microscopy (SEM) photomicrographs of the cellulose before and after modification were observed by a Quanta 200 environmental scanning electron microscope (Philips-FEI Co., Holland) operated at an accelerating voltage of $5 \mathrm{kV}$, and the dried samples were coated with a gold layer using a diode sputter coating unit. Electron micrographs of each sample were recorded at a magnification of 500 .

\section{Adsorption of $\mathrm{Ca}^{2+}, \mathrm{Cu}^{2+}$ and $\mathrm{Pb}^{2+}$}

The adsorption experiments were performed on a platform shaker at $200 \mathrm{r} / \mathrm{min}$ and $25 \pm 2$ ${ }^{\circ} \mathrm{C}$ for $2 \mathrm{~h}$ using $100 \mathrm{~mL}$ shaker flask. Cations concentrations were analyzed using atomic absorption spectroscopy (PerkinElmer 3110, USA). The adsorption capacity $q_{e}(\mathrm{mg} / \mathrm{g})$ was calculated as described by the following equation:

$$
\mathrm{q}_{\mathrm{e}}=\left(\mathrm{C}_{\mathrm{o}}-\mathrm{C}_{\mathrm{e}}\right) \mathrm{V} / \mathrm{m} \quad \text { Eq. } 1
$$

Where, $C_{o}(\mathrm{mg} / \mathrm{L})$ is the initial metal ion concentration, $C_{e}$ is the metal ion equilibrium concentration, $V(\mathrm{~L})$ is the volume of the metal ion solution and $m(\mathrm{~g})$ is the mass of adsorbent.

\section{$\underline{\text { Results and Discussion }}$}

Synthesis of RAFT and Macro-RAFT agents

Cellulose was grafted with acrylic acid and methyl methacrylate in order to increase the chelating carboxylic groups on its surface. At first, a suitable RAFT agent namely; Benzylsu lfanylthiocarbonylsulfanyl-propionic acid was synthesized according to Scheme1.

As shown in Fig. 1, the ${ }^{1} \mathrm{HNMR}$ of the prepared RAFT agent revealed $3 \mathrm{CH} 2$ groups which correspond to 2 triplets bands at $1.85,2.5$ and singlet band at and $4.5 \mathrm{ppm}$ [23].

After that a macro RFAT agent was prepared by introducing the RAFT agent (1) onto the surface of cellulose via Steglich esterification mechanism, in presence of dicyclohexylcarbodiimide (DCC) as a coupling reagent and 4-dimethylaminopyridine (DAMP) as a catalyst. This reaction generally takes place at room temperature using dichloromethane as a solvent, as illustrated in Scheme 2.

Egypt.J.Chem. 62, No.1 (2019) 
<smiles>O=C(O)CCSC(=S)SC1CCCCC1</smiles>

Carbon disulfide 3-mercaptopropanoic acid<smiles>CC(C)CCc1ccccc1</smiles><smiles>O=C(O)CCSC(=S)SCc1ccccc1</smiles>

3-(((benzylthio)carbonothioyl)thio)propanoic acid

Scheme 1. Synthesis of RAFT agent.
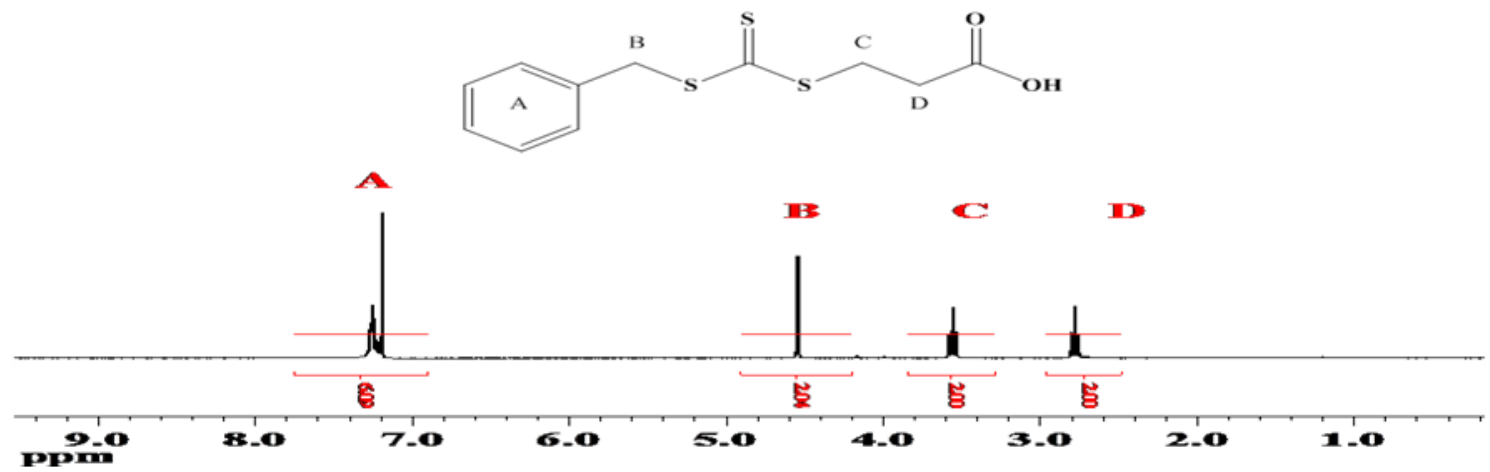

Fig.1. ${ }^{1} \mathrm{H}$ NMR of RAFT agent in CDCl3.<smiles>[R]C([R6])([Y20])[3H]</smiles><smiles>O=C(CCSC(=S)SCc1ccccc1)OC[C@H]1OC[C@H](O)[C@@H](O)[C@H]1O</smiles>

Scheme 2. Functionalization of cellulose by RFAT agent via Steglich esterification mechanism to produce Macro-RAFT agent. 
FT-IR of cellulose and its graft Copolymers

The FTIR spectra of cellulose, cellulose-RAFT and its graft copolymers are shown in figures 2 and 3 . In the spectrum of cellulose and celluloseRAFT (Fig. 2), a characteristic stretching vibration band of carbonyl group $(\mathrm{C}=\mathrm{O})$ at around 1750 $\mathrm{cm}-1$ appeared that is related to the RAFT agent.

After that, the RAFT polymerization of acrylic acid (AA) and methyl methacrylate (MMA) took place in THF using AIBN as azo initiator at 70 ${ }^{\circ} \mathrm{C}$. At first a homo-polymer of acrylic acid was grafted onto the cellulose surface. The grafting reaction was followed by FTIR (Fig. 3). The characteristic absorption peaks of grafted cellulose with AA and MMA appeared at about $1800 \mathrm{~cm}^{-1}$ due to the aliphatic $\mathrm{C}-\mathrm{H}$ stretching vibration of the monomeric repeating units and a carbonyl $(\mathrm{C}=\mathrm{O})$ stretching vibration at around $1750 \mathrm{~cm}^{-1}$ were present, respectively [24, 25].

A portion of acrylic acid (AA) was replaced by methyl methacrylate (MMA) in order to insert MMA segments between AA polymer chains.

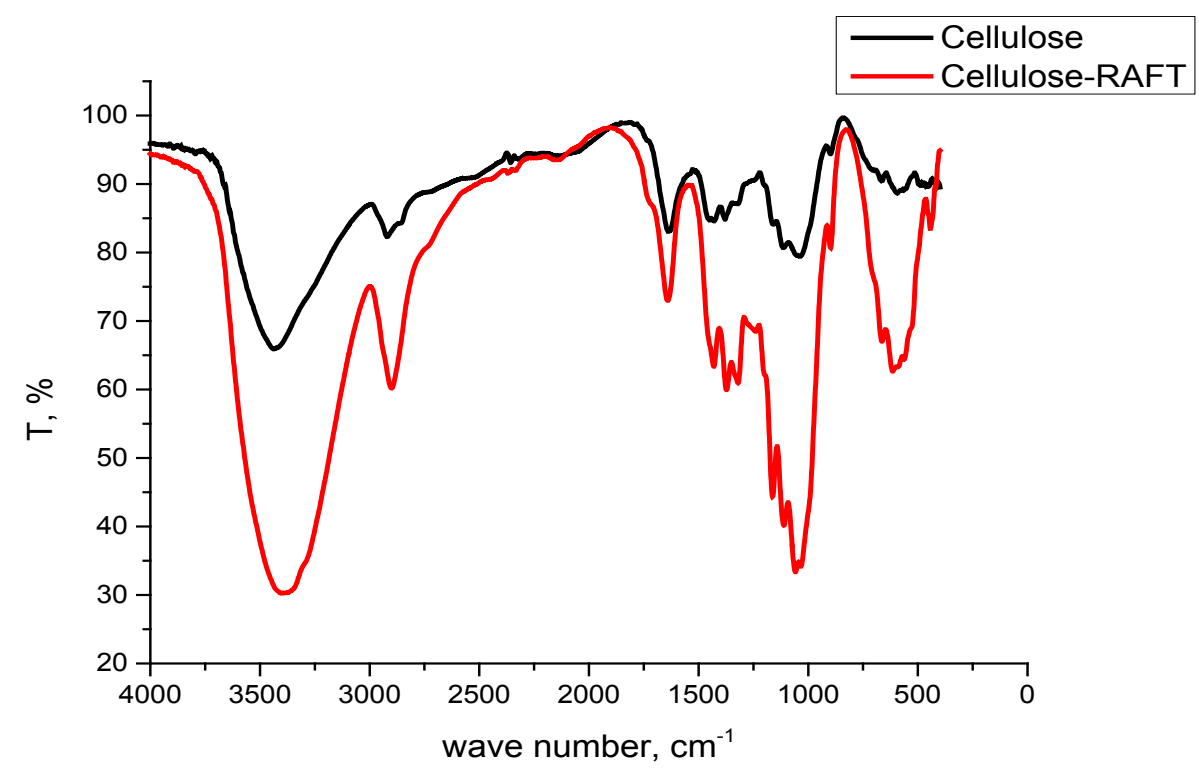

Fig. 2. FT-IR of neat cellulose and Cellulose-RAFT.

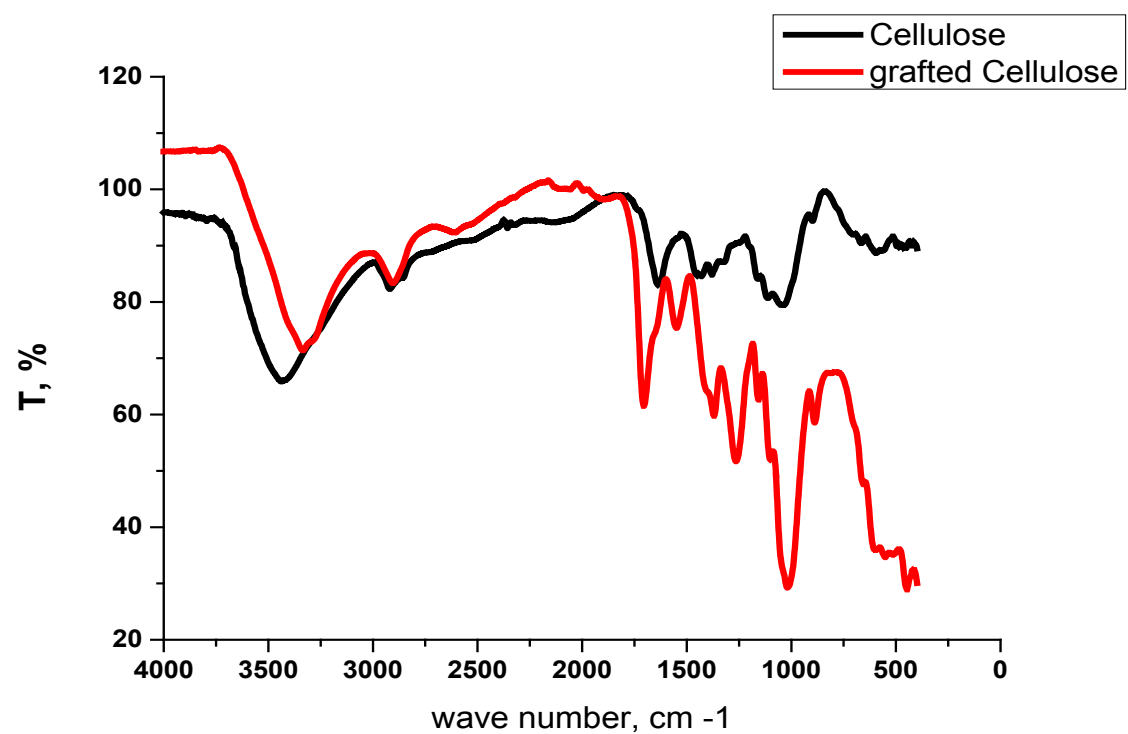

Fig. 3. FT-IR of Cellulose and grafted Cellulose. 
This step aims to increase the spaces between the pendant carboxylic groups in AA moieties on the cellulose surface. The AA/MMA ratios were shown in Table 1.

Cleaving of polymer chains from cellulose backbone

Two transesterification methods were studied to hydrolyze the PAA and PAA-co-PMMA chains from cellulose. The hydrolyzed products were subjected to GPC and ${ }^{1} \mathrm{H}$ NMR analyses. In Fig. 4 and 5, the ${ }^{1} \mathrm{HNMR}$ spectra of hydrolyzed PAA and PAA-co-PMMA are represented. The peaks assignments were done easily.
The molecular weights of the hydrolyzed samples were represented in Table 1 and the GPC elugrams are plotted in Fig. 6. The Mn values of the hydrolyzed polymers are slightly decreased as the amount of the PMMA increased in the matrix. The PDIs values are within the normal range of the common values obtained by RAFT polymerization. A slight elevation was observed in the PDI values in case polymers containing higher amount of PMMA as also indicated by the shoulder in the GPC elugram (Table 1 sample 5).

Scanning Electron Microscopy

SEM micrographs of cellulose and grafted

TABLE 1. GPC analysis of PAA-co-PMMA at different AA/MMA ratios.

\begin{tabular}{cccc}
\hline Code & $\begin{array}{c}\text { AA/MMA } \\
\text { molar ratio, \% }\end{array}$ & GPC analysis of hydrolyzed samples & Pn \\
\hline 1 & $100 / 0$ & 12000 & 1.10 \\
2 & $95 / 05$ & 11500 & 1.30 \\
3 & $90 / 10$ & 10200 & 1.20 \\
4 & $85 / 15$ & 9500 & 1.20 \\
5 & $75 / 25$ & 9100 & 1.30 \\
\hline
\end{tabular}

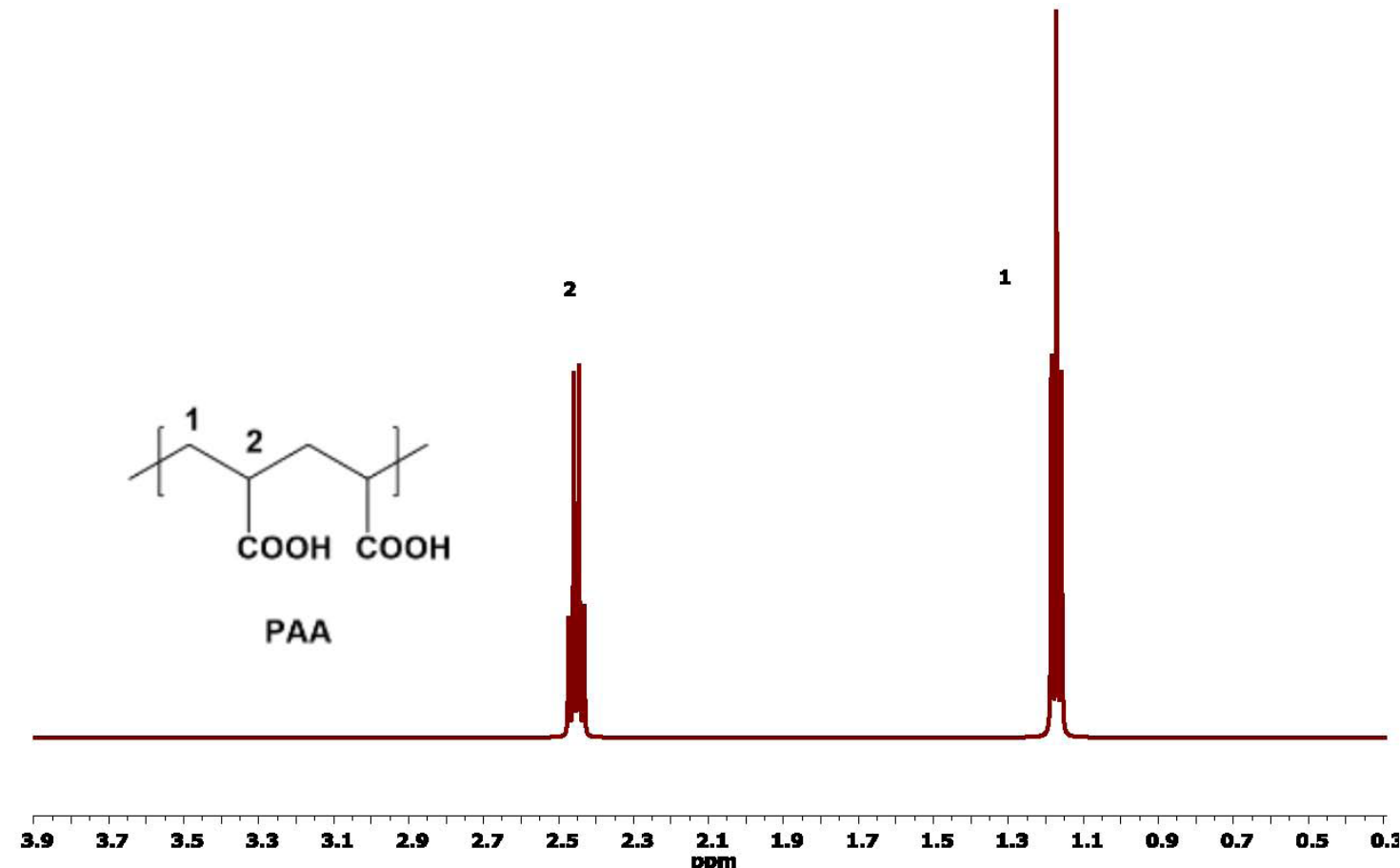

Fig. 4. ${ }^{1}$ HNMR of hydrolyzed PAA. 


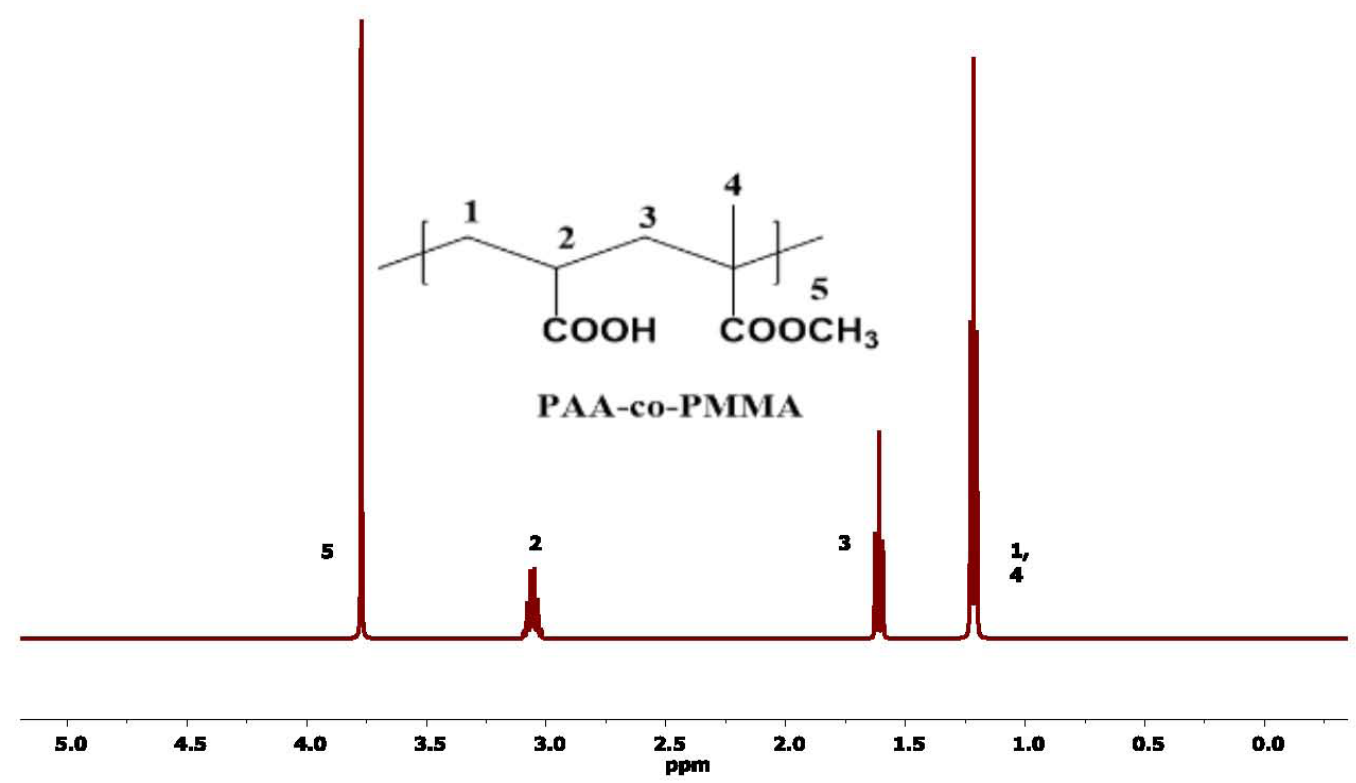

Fig.5. 'HNMR of hydrolyzed PAA-co-PMMA.

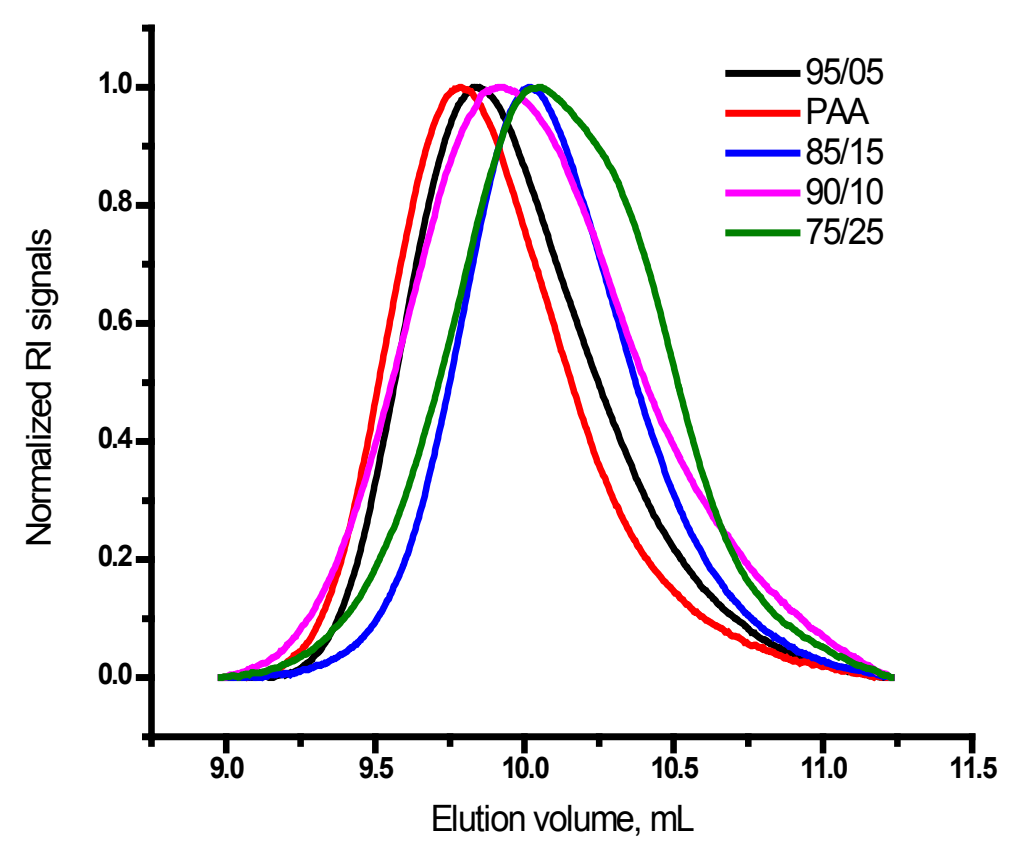

Fig. 6. GPC Elugrams of the hydrolyzed polymers. 
cellulose PAA-co-PMMA with AA/MMA 75/25 molar ratio\% copolymers are shown in Fig. 7. From Fig. 7, it is evident that the grafted and ungrafted cellulose have different structural features. The surface of the modified cellulose is smoother, less fractured, that is due to the entanglement of the polymeric chains.

\section{Thermo gravimetric analysis}

Figure 8 displays the thermal gravimetric analysis of unmodified cellulose fiber and cellulose-g- PAA-co-PMMA (AA/MMA 75/25 molar ratio). It demonstrates that the thermal stability of the grafted cellulose is higher than that of cellulose itself in the temperature range of $25-600^{\circ} \mathrm{C}$. As cellulose-g- PAA-co-PMMA
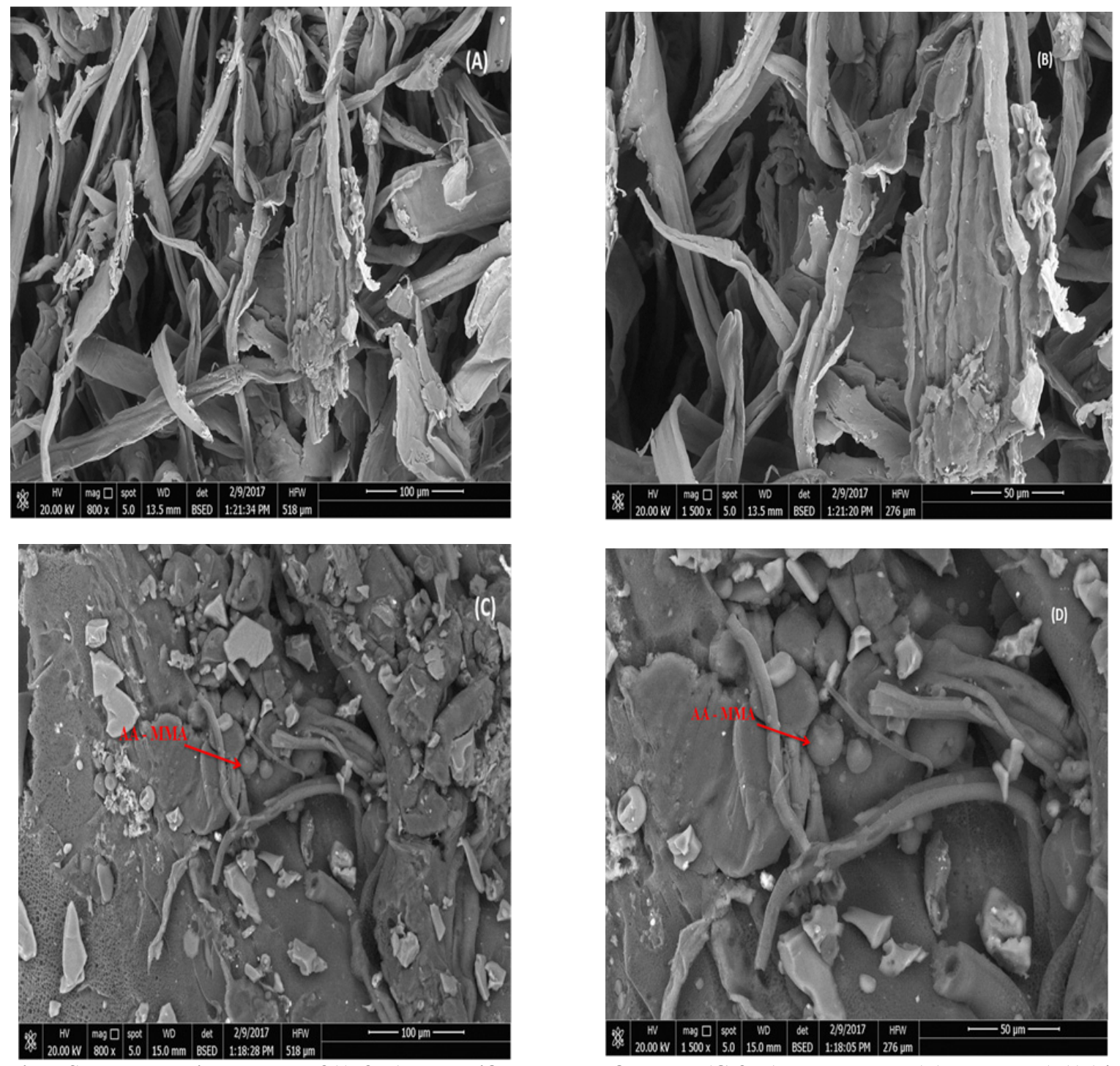

Fig.7. SEM photomicrographs of (A \& B) unmodified cellulose fiber and (C \& D) cellulose-g- PAA-co-PMMA (AA) MMA 75/25 molar ratio).

Egypt.J.Chem. 62, No.1 (2019) is hygroscopic, nearly 10 wt \% weight losses have occurred at $100^{\circ} \mathrm{C}$, due to the evaporation of residual water compared to only $8 \mathrm{wt} \%$ weight loss for the cellulose. In case of cellulose-gPAA-co-PMMA, In case of cellulose-g-PAA-coPMMA, a considerable enhancement in thermal stability has been noticed as compared with the ungrafted cellulose; however, a considerable enhancement in thermal stability has been seen. As the temperature increases, the main mass loss of the grafted cellulose starts at about $420^{\circ} \mathrm{C}$ corresponding to cellulose degradation at $420^{\circ} \mathrm{C}$. Finally, weight loss for cellulose is much more than that of grafted cellulose. So, the grafting of cellulose can enhance the thermal stability of cellulose. 


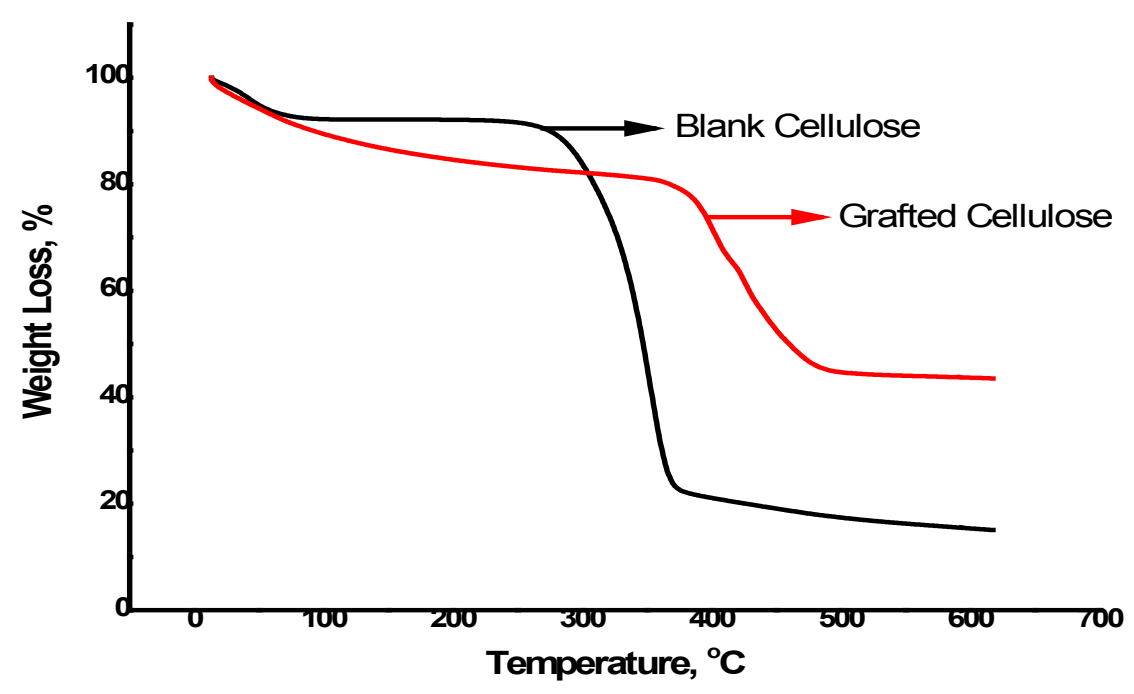

Fig. 8. TGA of cellulose fiber and cellulose-g- PAA-co-PMMA (AA/MMA 75/25 molar ratio).

\section{Metal ion adsorption}

We have screened the grafted cellulose samples on $\mathrm{Ca}^{++}(250 \mathrm{mg} / \mathrm{L}), \mathrm{Cu}^{++}(30 \mathrm{mg} / \mathrm{L})$ and $\mathrm{Pb}^{++}(30 \mathrm{mg} / \mathrm{L})$ solutions to test their adsorption activity in removing $\mathrm{Ca}^{++}, \mathrm{Cu}^{++}$and $\mathrm{Pb}^{++}$cations. Cations concentrations were analyzed using atomic absorption spectroscopy. The adsorption capacity $q_{e}(m g / g)$ was calculated as described in equation 1 .

The data presented in Fig. 9 and 10 revealed the improvements in the adsorption process with using grafted cellulose on the three tested cations. The grafted cellulose showed good adsorption performance for $\mathrm{Ca} 2+$ ion with $97 \%$ rather than $\mathrm{Cu}++$ and $\mathrm{Pb}++$. The adsorption studies demonstrated that the adsorption process of metal ions decreased with increasing MMA ratio in the cellulose-g-PAA-co-PMMA. In other words, the adsorption capability of cellulose-g-PAAco-PMMA could be enhanced by increasing the $\mathrm{COOH}$ groups of acrylic acid that improve the chelation activity of the grafted cellulose.

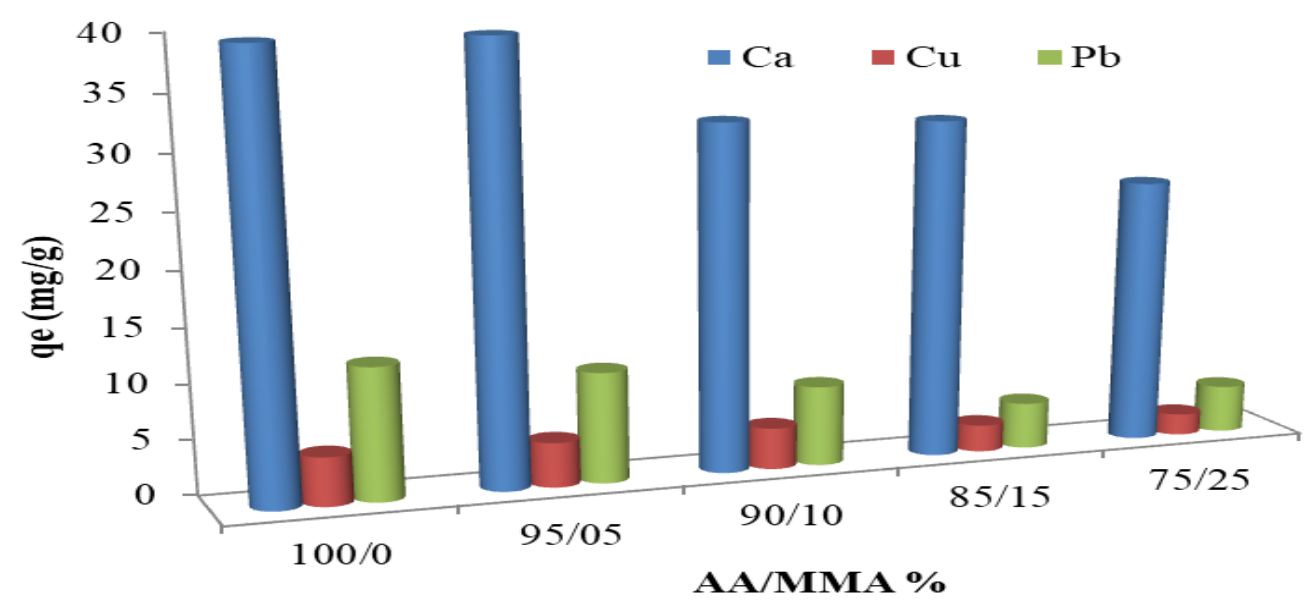

Fig. 9. Effect of AA/MMA ratios on adsorption capacity of grafted cellulose. 


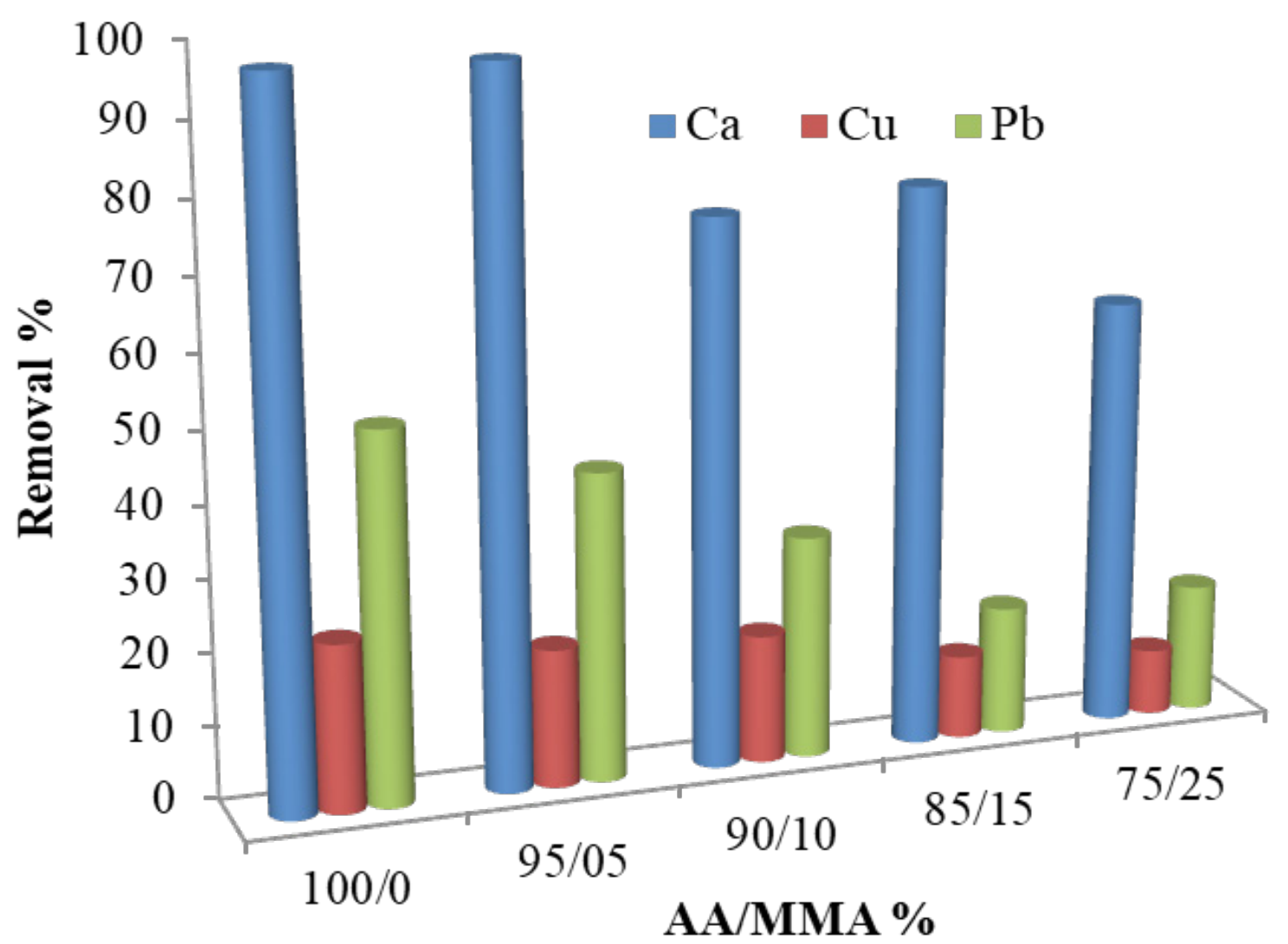

Fig. 10. Effect of AA/MMA ratios on Removal \% of grafted cellulose.

\section{Conclusion}

The graft copolymerization of acrylic acid and methylmethacrylate onto cellulose was successfully carried out by RAFT Polymerization, which considered as one of the most versatile method that gives a well-defriend polymeric chains with narrow disperse polymers. The grafting process was confirmed by the characterization of FTIR, TGA, and SEM. The grafted cellulose showed good adsorption performance for $\mathrm{Ca}^{2+}$ and $\mathrm{Pb}^{2+}$ ions than $\mathrm{Cu}^{2+}$ ion. The studies of adsorption demonstrated that the grafting of cellulose with acrylate copolymers is promising in removing $\mathrm{Ca} 2+$ ions from aqueous solutions.

\section{Conflict of Interests}

The authors declare that they have no conflict to interests.

\section{Acknowledgment}

The authors acknowledge the Science and Technology Development Fund (STDF), Egypt for financial support of the research activities related to project; Project ID 15203.

\section{$\underline{\text { References }}$}

1. Ahmad M., Ahmed S., Swami B., Ikram S., Adsorption of heavy metal ions: role of chitosan and cellulose for water treatment. International Journal of Pharmacognosy. 2(6), 280 (2015).

2. El-Sakhawy M., Kamel S., Salama A., Youssef M.A., Teyor W., Tohamy H.A., Amphiphilic Cellulose as Stabilizer for Oil/Water Emulsion. Egypt. J. Chem. 60(2), 181 (2017).

3. Kamel S., Ibrahim M.B.M., Sher A. K., Decontamination of Manganese and Phenol from Aqueous Media by Sunflower Stems. International Journal of Polymeric Materials. 58, 533 (2009).

4. Kamel S., Abou-YousefH., Yousef M., El-Sakhawy M., Potential use of bagasse and modified bagasse for removing of iron and phenol from water. Carbohydrate Polymers. 88, 250 (2012).

5. Kamel S., Ali N., Jahangir K., Shah S.M., El-Gendy A.A., Pharmaceutical significance of cellulose: A review. Express Polymer Letters. 2(11), 758 (2008). 
6. Klemm D., Heublein B., Fink H.P., Bohn A., Cellulose: fascinating biopolymer and sustainable raw material. Angew. Chem., Int. Ed. 44, 3358 (2005).

7. Nishiyama Y., Sugiyama J., Chanzy H., Langan P., Crystal structure and hydrogen bonding system in cellulose I $\alpha$ from synchrotron x-ray and neutron fiber diffraction. J. Am. Chem. Soc. 125, 14300 (2003).

8. Kamel S., Hassan E.M., El-Sakhawy M., Preparation and application of AcrylonitrileGrafted cyannoethyl cellulose for the removal of $\mathrm{Cu}$ (II) ions. Journal of Applied Polymer Science. 100, 329 (2006).

9. Kamel S., Ibrahim M.B.M., Sher A.K., Decontamination of Manganese and Phenol from Water with Modified Sunflower Stem. International Journal of Polymeric Materials. 58, 533 (2009).

10. Kamel S., Abou-Yousef H., Yousf V., Potential uses of bagasse and modified bagasse for removal of iron and phenol from water. Carbohydrate Polymers. 88, 250 (2012).

11. Qiu J., Charleux B., Matyjaszewski K. Controlled/ living radical polymerization in aqueous media: homogeneous and heterogeneous system. Prog Polym Sci. 26, 2083 (2001).

12. Roy D., Guthrie J.T, Perrier S., RAFT graft polymerization of 2-(Dimethylaminoethyl) Methacrylate onto cellulose fibre. Aust J Chem. 59, 737 (2006).

13. Carlmark A., Malmstrom E.E., ATRP grafting from cellulose. fibers to create block-copolymer grafts. Biomacromolecules. 4, 1740 (2003).

14. Shen D.W., Yu H., Huang Y., Densely grafting copolymers of ethyl cellulose through atom transfer radical polymerization. J Polym Sci Part A Polym Chem. 43, 4099 (2005).

15. Shen D., Yu H., Huang Y., Synthesis of graft copolymer of ethyl cellulose through living polymerization and it's self-assembly. Cellulose. 13, 235 (2006)

16. You Y.Z., Hong C.Y., Bai R.K., Pan C.Y., Wang J.S., Photo-Initiated Living Free Radical Polymerization in the Presence of Dibenzyl Trithiocarbonate. Macromol. Chem. Phys. 203,
477 (2002).

17. Hong C.Y., You Y.Z., Bai R.K., Pan C.Y., Borjihan G., Controlled polymerization of acrylic acid under ${ }^{60} \mathrm{Co}$ irradiation in the presence of dibenzyl trithiocarbonate. J Polym. Sci., Polym. Chem. 39, 3934 (2001).

18. Bai R.K., You Y.Z., Pan C.Y., ${ }^{60} \mathrm{Co} \gamma$-IrradiationInitiated "Living" Free-Radical Polymerization in the Presence of Dibenzyl Trithiocarbonate. Macromol. Rapid Commun., 22, 315 (2001).

19. Roy D., Guthrie J.T., Perrier S., Graft Polymerization: Grafting Poly(styrene) from Cellulose via Reversible Addition-Fragmentation Chain Transfer (RAFT) Polymerization. Macromolecules. 38, 10363 (2005).

20. Perrier S., Takolpuckdee P., Westwood J., Lewis D.M., Versatile Chain Transfer Agents for Reversible Addition Fragmentation Chain Transfer (RAFT) Polymerization to Synthesize Functional Polymeric Architectures. Macromolecules. 37(4), 2709 (2004).

21. Justin O. Zoppe, Nariye Cavusoglu Ataman, Piotr Mocny, Jian Wang, John Moraes, and Harm-Anton Klok, Surface-Initiated Controlled Radical Polymerization: State-of-the-Art, Opportunities, and Challenges in Surface and Interface Engineering with Polymer Brushes, Chem. Rev., 117, 1105-1318 (2017)

22. Cai, T., Yang, Z., Li, H. et al. Effect of hydrolysis degree of hydrolyzed polyacrylamide grafted carboxymethyl cellulose on dye removal efficiency. Cellulose, 20, 2605 (2013).

23. Bontempo D., Masci G., Leonardis P.D., Mannina L., Capitani D., Crescenzi V., Versatile grafting of polysaccharides in homogeneous mild conditions by using atom transfer radical polymerization. Biomacromolecules. 7, 2154 (2006).

24. Nada A. M. A., Kamel S., Abd El-Sayed E. S., Infrared spectroscopy and thermal analysis of chitosan and its derivatives. Energy Education Science and Technology. 18(1), 17 (2006).

25. Yan L.F., Tao W., Graft copolymerization of, NNmethylacrylamide to cellulose in homogeneous media using atom transfer radical polymerization for hemocompatibility. .J. Biomedical Science and Engineering. 1, 37 (2008).

(Received 31/5/2018; accepted 6/9/2018 


\section{تخليق سيليلوز مطعم بالاكريلات عن طريق البلمرة الجذرية RAFT وتطبيقه كمادة مازة

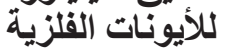

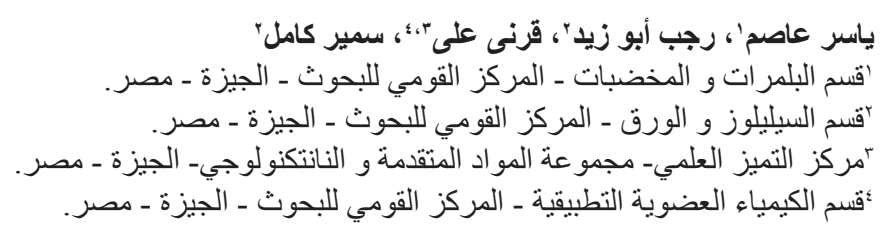

في هذا البحث تم تطعيم السيليلوز ببوليمر ات حمض الاكريكلك وميثيل ميثاكريلات وذللك بطريقة بلمرة انتقال

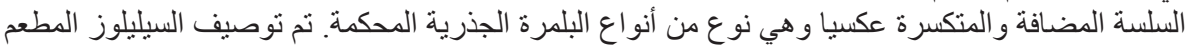

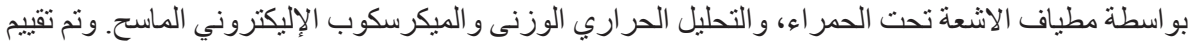

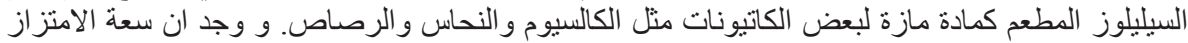

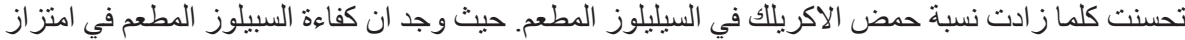

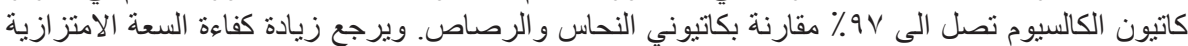

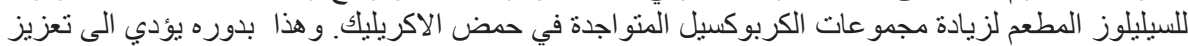

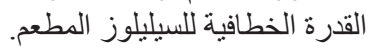

